\title{
TP53 Status and Response to Chemotherapy in Breast Cancer
}

\author{
Philippe Bertheau ${ }^{a}$ Marc Espiéb Elisabeth Turpin ${ }^{c}$ Jacqueline Lehmann ${ }^{c}$ \\ Louis-François Plassa ${ }^{c}$ Mariana Varna ${ }^{a}$ Anne Janin ${ }^{a}$ Hugues de Théc

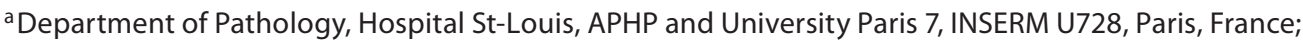 \\ ${ }^{b}$ Department of Oncology, Hospital St-Louis, APHP and University Paris 7, Paris, France; \\ 'Department of Biochemistry, Hospital St-Louis, APHP and University Paris 7, CNRS UMR7151, Paris, France
}

\section{Key Words}

p53 - TP53 - Breast cancer · Chemotherapy • Anthracycline • Taxanes $\cdot$ Alkylating agents

\begin{abstract}
Despite its central role in the control of apoptosis, senescence and cell cycle arrest, the tumor suppressor protein p53 remains an enigma for its possible role in predicting response to chemotherapy in cancer patients. Many studies remained inconclusive, others showed a better response for tumors with normal p53, and some recent studies showed adverse effects of normal p53 for response to treatment. p53 is not only a powerful pro-apoptotic factor in response to drug-induced DNA damages but also a potential inducer of cell cycle arrest, protecting tumor cells from further cytotoxic damages. Our review describes the classical as well as the more recent concepts. In order to draw definite conclusions, future works should use more reliable methods to assess the TP53 status and should address more homogeneous tumor subpopulations treated with homogeneous chemotherapy regimens.

Copyright $\odot 2008$ S. Karger AG, Basel
\end{abstract}

\section{Introduction}

Chemotherapy has become an essential part of breast cancer treatment in adjuvant [1] or neoadjuvant settings [2]. Response to chemotherapy is one of the most important prognostic factors, especially when pathological complete response is achieved [3-5].

Drug resistance can occur at many levels, including increased drug efflux, drug inactivation, alterations in drug target and evasion of apoptosis [6]. Apoptosis is indeed one of the main pathways involved in tumor response to treatment [7], as well as senescence [8].

p53 regulates the cell fate in response to various stresses, either genotoxic (DNA alterations induced by irradiation, UV, carcinogens, cytotoxic drugs) or not genotoxic (hypoxia, nucleotide depletion, oncogene activation, microtubule disruption, loss of normal cell contacts) [9]. p53 can induce transient or prolonged (senescence-like) cell cycle arrest, irreversible cell cycle arrest (senescence) or apoptosis. It may also promote DNA repair and inhibit angiogenesis. The qualitative and quantitative activity of p53 depends on its integrity (mutation status), its amount and its specific posttranslational modifications induced by different stress-induced signaling pathways. This leads to variable patterns of association between p53 and a number of other coregulatory proteins, of which some may be tissue or cell type specific, as well as many differ-

Philippe Bertheau

Laboratory of Pathology, Hospital Saint-Louis

1 avenue C. Vellefaux

FR-75010 Paris (France)

Tel. +33 142494 135, Fax +33 142494 516, E-Mail philippe.bertheau@sls.aphp.fr 
ent target genes. Despite this complexity, p53 activity has been associated with prognosis and prediction of tumor response to various therapies. This review shows that beside its role in the induction of apoptosis and subsequent tumor regression in response to treatment, in other settings, p53 may also preferentially induce cell cycle arrest and contribute to treatment resistance.

\section{Biology of p53}

The p53 protein is encoded by the TP53 gene, located at $17 \mathrm{p} 13$. Three functionally distinct regions have been identified in p53: an acidic $\mathrm{N}$-terminal region (codons 1-101), containing a transactivation acidic domain, and a proline-rich domain required for interaction with various proapoptotic proteins, a DNA-binding domain localized in the core region of the protein (codons 102-292), and a basic C-terminal region (codons 293-393) involved in tetramerization and regulation of p53 activity.

In normal cells without stress, p53 activity is very low. Upon stress, p53 is activated through a series of posttranslational modifications and binds to specific DNA sequences. The p53 response elements are highly heterogeneous and have been found in several hundred genes that are induced or repressed, depending on the type of tissue and stress $[10,11]$.

Apoptosis appears as the critical function of p53 for tumor suppression $[12,13]$, and p53 controls the expression of genes associated with both apoptotic pathways, either extrinsic or intrinsic. The central core region of p53 has a major role in regulating apoptotic function. When the cell is not pushed towards a programmed cell death pathway, p53 can mediate the arrest of cells at 1 of 2 major cell-cycle checkpoints, in G1 (role played by p21 $1^{\text {WAF1-CIP1) }}$ or in G2 before mitosis (roles for GADD45

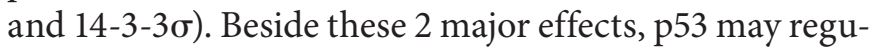
late angiogenesis and DNA repair.

p53 is highly regulated through several mechanisms. Posttranslational modification is a major mechanism regulating p53 function. p53 may be phosphorylated, acetylated, methylated, ubiquitinated, sumoylated, neddylated or glycosylated at multiple sites [14].

Furthermore, a considerable number of other proteins, some of them having tissue-specific expression [15], can bind to various regions of the p53 protein and modulate its activity. MDM2 is a major regulator of the p53 level [16]. It binds to the N-terminal region and represses $\mathrm{p} 53$ activity via 2 mechanisms: by promoting p 53 export to the cytoplasm and its consequent degradation, and by blocking p53 transcriptional activation. Levels of MDM2 can have profound impacts on survival and tumorigenesis [17]. More recently, MDM4 emerged as an important downregulator of the p53 function [18].

One important question has yet no clear answer: how does p53 'choose' between apoptosis or cell cycle arrest? This choice likely involves numerous factors. In a quantitative model, genes involved in growth arrest contain high-affinity $\mathrm{p} 53$ binding sites in their promoter, while low-affinity sites are present in the promoter of apoptosis-related genes [19]. Therefore, increased levels of p53 could lead to the onset of apoptosis by achieving a certain threshold level. However, the apoptotic targets of p53 do not necessarily contain low-affinity promoters. Moreover, as discussed below (see TP53 and Response to Chemotherapy: A Double-Edged Sword?), the observations that high-dose and dose-intense anthracyclines/ alkylating agent treatments may preferentially induce cell cycle arrest [20] argue against this model. Thus, the quantitative model is not sufficient. In a qualitative model, the preferential activation of apoptotic genes by p53 is mediated through the interaction of transcription coactivators. For instance, ASPP1 and ASPP 2 can both favor the interaction of $\mathrm{p} 53$ with the promoter of the proapoptotic gene BAX, but not that of MDM2 or p21 [13]. The proapoptotic effects of ASPP1 and ASPP2 may be counteracted by inhibitor of ASPP. p63 and p73, other members of the p53 family, could also favor selective binding of $\mathrm{p} 53$ to apoptotic promoters BAX, PMAIP1/ NOXA and PERP [13]. Nuclear factor- $\kappa B$-mediated upregulation of antiapoptotic gene targets can antagonize the proapoptotic functions of p53 [21]. Chromatin-associated proteins may also interact with p53 [22]. Several other comodulators or post-transcriptional changes that may influence the balance between apoptosis induction and cell cycle arrest are reviewed in Lacroix et al. [14].

\section{TP53 Mutations in Breast Cancer}

Somatic TP53 missense mutations are found in approximately $50 \%$ of human cancers $[23,24]$. More than 90\% TP53 mutations have been found in the DNA-binding domain, but examination of the whole TP53 coding sequence is beginning to reveal an increasing number of mutations in the $\mathrm{N}$ and $\mathrm{C}$ termini of the protein [25]. Twenty to $35 \%$ of breast tumors bear a TP53 mutation, some tumor subtypes being more often mutated [26]. Over 1,400 TP53 mutations have been described in 
breast cancers [27]. Most mutant p53 have impaired transactivation and may have dominant negative effects [28]. Some p53 mutations are only partially inactivating $[29,30]$ or even express an apoptotic activity higher than that of wild-type p53. Indeed, penetrance of each p53 mutant may be influenced by various factors such as normal genetic background, other genetic alterations in the tumor, tissue specificity and other unknown factors [31].

Mutant p53 proteins generally have an increased stability and accumulate in the nucleus of tumor cells and may be detectable by immunohistochemistry. It is believed that this is a consequence of the inactive p53 mutant protein not inducing the MDM2 protein required to target its own degradation. However, this mechanism may not be that simple [31].

\section{Prognostic Significance of the TP53 Status in Breast Cancer}

The possible links between p53 alterations and the other clinico-pathological characteristics have been widely investigated. Interpretation of prognostic data has often been complicated by the fact that most initial studies used immunohistochemistry to detect accumulation of p53, while analysis of the p53 pathway used other methods such as direct sequencing [32], functional tests [33] or transcriptome analysis [34].

Breast tumors showing immunostaining for p53 are more frequently estrogen receptor negative and progesterone receptor negative. They have been associated with a high proliferation rate, high histological grade, aneuploidy and poorer survival [35-37].

In a meta-analysis of 37 publications involving over 9,800 patients, the prognostic and predictive value of high p53 immunohistochemical expression in breast cancer was weak [38]. However, strong prognostic significance of TP53 mutations using sequencing has been reported in more than 25 studies involving over 6,000 patients [for review, see 39]. In 250 breast tumors, a 32 gene expression p53 signature outperformed sequencebased assessments of TP53 in predicting prognosis [34].

The prognostic significance of all types of mutations is not the same, each mutant protein having its own properties [31]. For example, studies have shown that patients with mutations effecting or disrupting the zinc-binding domains L2 and L3 were related to a poor prognosis [for review, see 39].

\section{TP53 Status and Response to Chemotherapy in Breast Cancer}

Trying to predict the sensitivity of a given tumor for a given treatment is a crucial challenge for oncologists since response to the first drug association, either cytotoxic or cytostatic, is strongly linked to overall prognosis $[3,5]$.

Several approaches aim at giving the chemosensitivity status as quickly as possible before initiating systemic treatment: pharmacogenomic predictors [40] address the patient, while tumor-based tests either use in vitro response assays $[41,42]$ or molecular profiling.

It has often been suggested that functional p53 is necessary for the induction of response to genotoxic stress, such as cytotoxic chemotherapy, through a p53-dependant apoptotic pathway [43]. However, 20 years of intensive research and hundreds of papers have not yet provided a single and simple answer to the question: does $\mathrm{p} 53$ status have a predictive value for chemotherapy response? Most likely, there is no single answer to that question, since too many factors interact.

Ex vivo studies have yielded some general results regardless of the type of treatment. There is evidence from cell [44] and animal studies [45] that mutant p53 is associated with resistance to chemotherapy. Of 58 cell lines (lung, colon, breast, ovary, leukemia, melanoma, kidney, prostate, central nervous system) tested for chemosensitivity with 123 anticancer drugs [46], 8 were breast cancer cell lines: MCF-7, MCF-7/Adr, MDA-MB-231, Hs578T, MDA-MB-435, MDA-N, BT-549 and T-47D. All cell lines, except MCF-7, had a mutated p53. All other cell lines, except T-47D, were much less sensitive than MCF-7 cells. Using wild-type p53 cells and altered p53 daughter cells, Cimoli et al. [47] found that transfection with a wild-type p53 tends to increase sensitivity.

However, the situation is much more complex with in vivo studies, where treatments and tumor types are often heterogeneous.

\section{Anthracycline-Based Chemotherapy in vivo}

In a study of 63 patients with locally advanced breast cancers treated with neoadjuvant doxorubicin, specific mutations disrupting the zinc-binding domains correlated with primary resistance to the drug and were predictive of an early relapse [48]. These findings were confirmed in an extended study from the same group including 90 patients [49]. In a study of patients with advanced breast cancer treated with tamoxifen or upfront chemotherapy, Berns et al. [50] found that TP53 mutations were 
associated with a poor, although not significant, response to anthracycline-based chemotherapy. Rahko et al. [51] examined the predictive relevance of a mutated TP53 in a series of 254 samples from primary breast cancer patients. The response rate to anthracycline-based chemotherapy in metastatic disease was low in the p53-positive cases.

It has recently been suggested that the status of codon 72 polymorphism (Arg/Pro) could affect the response of cancer cells to chemotherapy, notably through a different interaction between p53 and p73 [52]. For instance, breast cancer patients with the Pro/Pro variant may be less sensitive to an anthracycline-based treatment than those with the Pro/Arg or Arg/Arg variant [53].

Beside these studies showing that TP53 mutations predict resistance to anthracycline-based treatments, other studies showed increased response rates for TP53 mutated tumors. These works are not contradictory but rather address different tumor subtypes and/or different drug regimens.

In 80 non-inflammatory locally advanced breast cancers treated with dose-intense epirubicin-cyclophosphamide combination, no complete pathological response was observed in 52 tumors without TP53 mutation, while $60 \%$ of the 28 tumors with TP53 mutations showed complete pathological response [20,54]. In these studies, TP53 was assessed with the yeast functional assay $[33,55]$ which detects $90 \%$ of reported mutations even if the tissue sample contains many non-tumor cells. Also, the treatment was both high dose and dose intense $(6$ cycles of $75 \mathrm{mg} / \mathrm{m}^{2}$ epirubicin and $1,200 \mathrm{mg} / \mathrm{m}^{2}$ cyclophosphamide, given every 14 days). These studies point to a strong predictive value of TP53 mutation for complete pathological response. Furthermore, despite the fact that TP53 mutated tumors usually have a worse prognosis, longer overall survivals were observed in TP53 mutated tumors. Subsequent expression profiles revealed that most responsive tumors were of the basal phenotype, a finding consistent with those of Rouzier et al. [56] where basallike tumors were more sensitive to paclitaxel and doxorubicin. In another recent study performed on 188 breast tumors with immunohistochemical detection of $\mathrm{p} 53$, p53-positive patients benefited more from high-dose chemotherapy than from standard chemotherapy [57].

\section{Non-Anthracycline Chemotherapy in vivo}

Johnson and Fan [58] found that human breast cancer BCap37 cells transfected with antisense p53 or $\mathrm{p} 21^{\mathrm{WAF} / \mathrm{CIP} 1}$ exhibited a significant increase in their sensitivity to paclitaxel. In 67 breast tumors treated either with neoadjuvant 5-fluorouracil epirubicin cyclophosphamide or paclitaxel chemotherapy, a combination of sequencing and immunohistochemical results revealed a significant association between abnormal p53 and response to paclitaxel. The efficiency of paclitaxel during mitosis might be supported by lack of G1 arrest due to p53 deficiency. Despite this trend for a better response to taxanes for TP53-mutated tumors [59], it is not yet possible to identify, before the initiation of therapy, the patients for whom docetaxel will be effective [60].

Geisler et al. [61] investigated 35 patients with locally advanced breast cancer for TP53 mutations before receiving combination chemotherapy with 5-fluorouracil and mitomycin. Mutations in the TP53 gene, in particular those affecting loop domains L2 or L3 of the p53 protein, were associated with lack of response to chemotherapy.

Andersson et al. [62] found that TP53 mutations (assessed by sequencing) might induce resistance to cyclophosphamide, methotrexate, 5-fluorouracil adjuvant treatment.

\section{Methodological Issues That May Limit the Power of Response Studies}

Most early studies have assessed the p53 status using immunohistochemistry and remained inconclusive with regard to chemoresponsiveness in breast cancers [63-65]. The correlation between p 53 accumulation measured by immunohistochemistry and p53 mutation detected by sequencing has been estimated to be less than $75 \%$ in breast carcinomas [32]. Indeed, not all mutations yield a stable protein, and some mutations lead to an abnormal protein not detected by immunohistochemistry. On the other hand, wild-type p53 may accumulate in some tumors as a result of the response to DNA damage, giving a positive immunohistochemistry result not accounting for TP53 mutation.

Many studies performed on locally advanced breast tumors have included both non-inflammatory and inflammatory tumors. This may have somehow obscured the possible impact of biological markers of response or survival, since inflammatory breast cancer is clinically, and also biologically, a different entity [66].

Another parameter that can strongly influence results is the method used to assess breast tumor response: clinical assessment has been used in many studies and is not sufficient to precisely define tumor response since edema and fibrosis can simulate residual tumor or, conversely, residual tumor can be microscopic and thus not detected through clinical examination. Pathological assessment of surgical specimens following chemotherapy is a much 
more reliable method to assess response to treatment when it is performed by experienced pathologists with a sufficient number of sampled tissue blocks. However, pathological assessment has its own limits, for instance, when surgery is conservative, and therefore, does not explore the entire breast.

\section{TP53 and Response to Chemotherapy:}

\section{A Double-Edged Sword?}

In an editorial, McGill and Fisher [67] referred to p53 as a 'double-edged sword'. In the same journal issue, Bunz et al. [68] reported, in an in vitro study of colon cancer cells, that p53 effects on drug responses varied dramatically depending on the drug. The p53-deficient cells were sensitized to the effects of anthracyclines, while p53 disruption rendered cells strikingly resistant to the effects of the antimetabolite 5-fluorouracil.

We already mentioned some physiological molecular factors that may account for the preferential activation of either apoptosis or cell cycle arrest. In patient care in oncology, other factors may further complicate the overall picture: drug types and doses, type of TP53 mutation and tissue type.

Observations made in vivo favor different ways of downstream p53 activation (fig. 1) depending on drug types, drug doses and drug associations. For anthracycline-based therapies, it seems that p53 would usually activate the apoptotic cascade rather than cell cycle arrest, accounting for better responses in tumors with normal TP53. However, drug doses may be crucial since highdose and dose-intense anthracycline regimens might preferentially induce prolonged cell cycle arrest [20]; this would allow the recovery of cells damaged by chemotherapy and would protect them from other drugs that target cycling cells such as alkylating agents and could explain the lack of response in TP53 mutation-negative tumors. In the same work, with the same high-dose and dose-intense drug combination, more than half of TP53-mutated tumors responded to treatment, probably through accumulation of DNA damage, abnormal mitoses and subsequent mitotic catastrophe. The mechanisms of mitotic catastrophe are unknown, but it likely results from a combination of deficient cell-cycle checkpoints (in particular the DNA structure checkpoints and the spindle assembly checkpoint) and cellular damage [69]. Conversely, non-responding TP53 mutated tumors could escape the response through accumulation of genetic abnormalities that would not lead to a mitotic catastrophe but rather to aneuploidy and subsequent growth advantage. Ongoing experiments on xenografted breast tumors with or without TP53 muta-

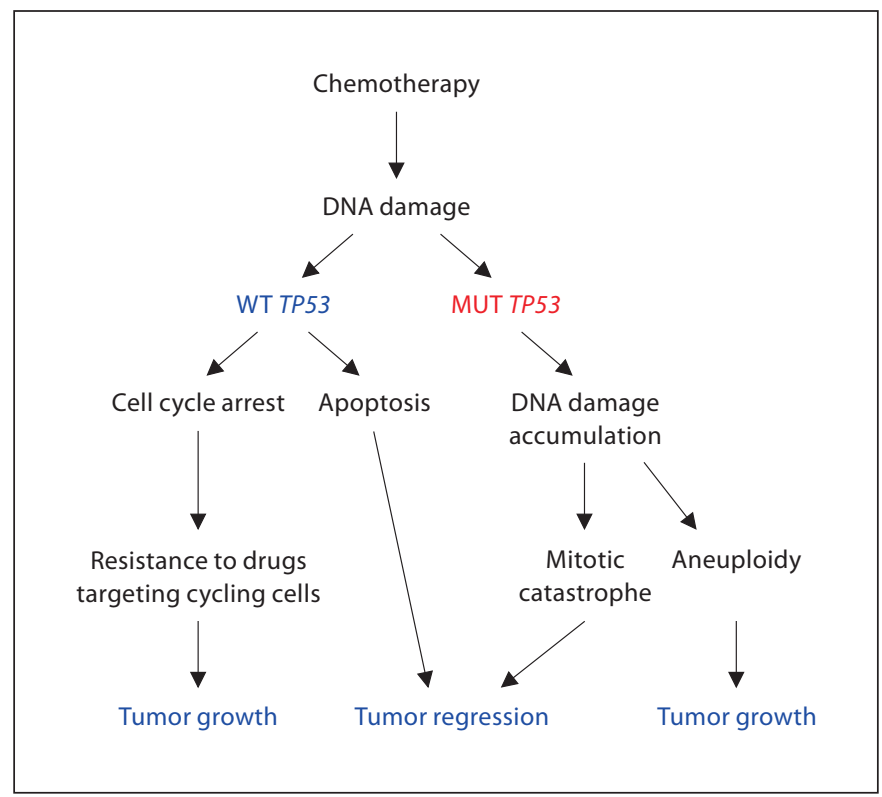

Fig. 1. In response to DNA-damaging chemotherapy such as anthracyclines, normal p53 may either induce apoptosis and tumor regression or cell cycle arrest making cells resistant to drugs that target cycling cells such as alkylating agents. Abnormal p53 may lead to accumulation of genetic abnormalities, either conferring tumor growth advantage through aneuploidy or inducing tumor regression through abnormal mitoses and mitotic catastrophe cell death. $\mathrm{WT}=$ Wild type; $\mathrm{MUT}=$ mutant.

tions and treated with epirubicin-cyclophosphamide tend to confirm these hypotheses (unpublished data). Close mechanisms could also explain why tumors expressing a mutant p53 seem to be more sensitive to paclitaxel and other mitotic spindle poisons.

Predictive value of the TP53 status may also depend on the type of mutation [31]. Geisler et al. [49] reported a poor response to low doses of doxorubicin in tumors having TP53 mutations affecting or disrupting the loop domains L2 or L3 of the p53 protein. However, the predictive value observed in Bertheau et al. [20] was not linked to the type of TP53 mutation.

Finally, p53 effect may depend on the tissue type, with several recent reports showing that TP53 mutated tumors in specific organs may respond better to treatment. In ovarian carcinomas, there seems to be an induction of cell cycle arrest rather than of apoptosis by p53 in response to platinum/taxane neoadjuvant therapy [70]. These findings support a model whereby p53-mediated cell-cycle arrest/ DNA repair could serve as a barrier to optimal chemotherapeutic treatment of ovarian and perhaps other carcinomas. In metastatic gastric cancer treated with high-dose 
etoposide, cisplatin and mitomycin, positive p53 immunostaining and positive 553 mutation status before chemotherapy were significantly associated with response to chemotherapy and prolonged overall survival [71].

Interestingly, p53 modulation of response to treatment might also be conditioned by the cellular target, the tumor stroma being a possible important target: Burdelya et al. [72] showed in mouse models that tumors with p53deficient stroma were more sensitive to cyclophosphamide, and the authors suggested this could be due to an increased sensitivity of p53-deficient endothelium to genotoxic stress.

\section{Conclusion}

The predictive value of TP53 mutations as a clinical biomarker in breast tumors has been intensively investigated. Despite these efforts, no consensus has been reached.
It appears now that p53 is not only a powerful proapoptotic factor that induces tumor cell death in response to drug-induced DNA damages, it can also be a powerful inducer of cell cycle arrest, protecting tumor cells from further cytotoxic damages, especially for high-dose and dose-intense epirubicin-cyclophosphamide regimen.

The $\mathrm{p} 53$ functional duality is also found when considering the possible use of p53 as a therapeutic target. p53 reactivation in p53-deficient tumors can induce either programmed cell death or cellular senescence $[73,74]$, but p53 inhibitory therapies could also be used to prevent the recovery of therapy-damaged tumor cells [75].

There is still a lot to be discovered about p53 and tumor cell response to treatment in breast cancers. Further studies should be performed with powerful and reliable methods to assess the TP53 status and should address highly homogeneous tumor subpopulations treated with homogeneous chemotherapy regimens.

\section{References}

1 Effects of chemotherapy and hormonal therapy for early breast cancer on recurrence and 15-year survival: an overview of the randomised trials. Lancet 2005;365:1687-1717.

-2 Kaufmann M, von Minckwitz G, Rody A: Preoperative (neoadjuvant) systemic treatment of breast cancer. Breast 2005;14:576581.

-3 Guarneri V, Broglio K, Kau SW, Cristofanilli M, Buzdar AU, Valero V, Buchholz T, Meric F, Middleton L, Hortobagyi GN, Gonzalez-Angulo AM: Prognostic value of pathologic complete response after primary chemotherapy in relation to hormone receptor status and other factors. J Clin Oncol 2006;24:1037-1044.

4 Michaelis LC, Ratain MJ: Measuring response in a post-RECIST world: from black and white to shades of grey. Nat Rev Cancer 2006;6:409-414.

5 Bertheau P, Lerebours F, Mounier N, de Roquancourt A, Espie M, Clot P, Servant JM, Misset JL, Marty M, Janin A: Prognostic significance of a combined clinicopathologic score for response to primary systemic therapy in locally advanced breast cancer. Oncol Rep 2005; 14:513-520.

6 Longley DB, Johnston PG: Molecular mechanisms of drug resistance. J Pathol 2005;205: 275-292.

7 Brown JM, Attardi LD: The role of apoptosis in cancer development and treatment response. Nat Rev Cancer 2005;5:231-237. $\checkmark 8$ Collado M, Blasco MA, Serrano M: Cellular senescence in cancer and aging. Cell 2007; 130:223-233.

-9 Royds JA, Iacopetta B: p53 and disease: when the guardian angel fails. Cell Death Differ 2006;13:1017-1026.

10 Qian H, Wang T, Naumovski L, Lopez CD, Brachmann RK: Groups of p53 target genes involved in specific p53 downstream effects cluster into different classes of DNA binding sites. Oncogene 2002;21:7901-7911.

11 Inga A, Storici F, Darden TA, Resnick MA: Differential transactivation by the p 53 transcription factor is highly dependent on p53 level and promoter target sequence. Mol Cell Biol 2002;22:8612-8625.

$>12$ Haupt S, Berger M, Goldberg Z, Haupt Y: Apoptosis - the p53 network. J Cell Sci 2003; 116:4077-4085.

13 Yu J, Zhang L: The transcriptional targets of p53 in apoptosis control. Biochem Biophys Res Commun 2005;331:851-858.

14 Lacroix M, Toillon RA, Leclercq G: p53 and breast cancer, an update. Endocr Relat Cancer 2006;13:293-325.

15 Soussi T, Wiman KG: Shaping genetic alterations in human cancer: the p53 mutation paradigm. Cancer Cell 2007;12:303-312.

16 Ringshausen I, O'Shea CC, Finch AJ, Swigart LB, Evan GI: Mdm2 is critically and continuously required to suppress lethal p53 activity in vivo. Cancer Cell 2006;10:501-514.
17 Vousden KH, Prives C: p53 and prognosis: new insights and further complexity. Cell 2005;120:7-10.

18 Toledo F, Wahl GM: Regulating the p53 pathway: in vitro hypotheses, in vivo veritas. Nat Rev Cancer 2006;6:909-923.

19 Chen X, Ko LJ, Jayaraman L, Prives C: p53 levels, functional domains, and DNA damage determine the extent of the apoptotic response of tumor cells. Genes Dev 1996;10: 2438-2451.

20 Bertheau P, Turpin E, Rickman DS, Espié M, de Reyniès A, Feugeas JP, Plassa LF, Soliman H, Varna M, de Roquancourt A, LehmannChe J, Beuzard Y, Marty M, Misset JL, Janin A, de Thé H: Exquisite sensitivity of TP53 mutant and basal breast cancers to a dosedense epirubicin-cyclophosphamide regimen. PLoS Med 2007;4:e90.

21 Tergaonkar V, Perkins ND: p53 and NF-kappaB crosstalk: IKKalpha tips the balance. Mol Cell 2007;26:158-159.

22 Tanaka T, Ohkubo S, Tatsuno I, Prives C: hCAS/CSE1L associates with chromatin and regulates expression of select p53 target genes. Cell 2007;130:638-650.

23 Petitjean A, Mathe E, Kato S, Ishioka C, Tavtigian SV, Hainaut P, Olivier M: Impact of mutant p53 functional properties on TP53 mutation patterns and tumor phenotype: lessons from recent developments in the IARC TP53 database. Hum Mutat 2007;28: 622-629. 
24 Soussi T, Ishioka C, Claustres M, Béroud C: Locus-specific mutation databases: pitfalls and good practice based on the p53 experience. Nat Rev Cancer 2006;6:83-90.

$\checkmark 25$ Vousden KH, Lu X: Live or let die: the cell's response to p53. Nat Rev Cancer 2002;2: 594-604.

-26 Turpin E, Bieche I, Bertheau P, Plassa LF, Lerebours F, de Roquancourt A, Olivi M, Espie M, Marty M, Lidereau R, Vidaud M, de The $\mathrm{H}$ : Increased incidence of ERBB2 overexpression and TP53 mutation in inflammatory breast cancer. Oncogene 2002;21:75937597.

-27 Olivier M, Langerod A, Carrieri P, Bergh J, Klaar S, Eyfjord J, Theillet C, Rodriguez C, Lidereau R, Bieche I, Varley J, Bignon Y, Uhrhammer N, Winqvist R, Jukkola-Vuorinen A, Niederacher D, Kato S, Ishioka C, Hainaut P, Borresen-Dale AL: The clinical value of somatic TP53 gene mutations in 1,794 patients with breast cancer. Clin Cancer Res 2006;12:1157-1167.

28 Willis A, Jung EJ, Wakefield T, Chen X: Mutant p53 exerts a dominant negative effect by preventing wild-type p53 from binding to the promoter of its target genes. Oncogene 2004;23:2330-2338.

-29 Friedlander P, Haupt Y, Prives C, Oren M: A mutant p53 that discriminates between p53responsive genes cannot induce apoptosis. Mol Cell Biol 1996;16:4961-4971.

-30 Rowan S, Ludwig RL, Haupt Y, Bates S, Lu X, Oren M, Vousden KH: Specific loss of apoptotic but not cell-cycle arrest function in a human tumor derived p53 mutant. EMBO J 1996;15:827-838.

- 31 Soussi T: p53 alterations in human cancer: more questions than answers. Oncogene 2007;26:2145-2156.

- 32 Norberg T, Lennerstrand J, Inganas M, Bergh $\mathrm{J}$ : Comparison between p53 protein measurements using the luminometric immunoassay and immunohistochemistry with detection of p53 gene mutations using cDNA sequencing in human breast tumors. Int $\mathrm{J}$ Cancer 1998;79:376-383.

- 33 Flaman JM, Frebourg T, Moreau V, Charbonnier F, Martin C, Chappuis P, Sappino AP, Limacher IM, Bron L, Benhattar J, et al: A simple p53 functional assay for screening cell lines, blood, and tumors. Proc Natl Acad Sci USA 1995;92:3963-3967.

-34 Miller LD, Smeds J, George J, Vega VB, Vergara L, Ploner A, Pawitan Y, Hall P, Klaar S, Liu ET, Bergh J: An expression signature for p53 status in human breast cancer predicts mutation status, transcriptional effects, and patient survival. Proc Natl Acad Sci USA 2005; 102:13550-13555
35 Bonnefoi H, Diebold-Berger S, Therasse P, Hamilton A, van de Vijver M, MacGrogan G, Shepherd L, Amaral N, Duval C, Drijkoningen R, Larsimont D, Piccart M: Locally advanced/inflammatory breast cancers treated with intensive epirubicin-based neoadjuvant chemotherapy: are there molecular markers in the primary tumour that predict for 5 year clinical outcome? Ann Oncol 2003; 14: 406-413.

36 Hensel M, Schneeweiss A, Sinn HP, Egerer G, Solomayer E, Haas R, Bastert G, Ho AD: p53 is the strongest predictor of survival in highrisk primary breast cancer patients undergoing high-dose chemotherapy with autologous blood stem cell support. Int J Cancer 2002;100:290-296.

37 Malamou-Mitsi V, Gogas H, Dafni U, Bourli A, Fillipidis T, Sotiropoulou M, Vlachodimitropoulos D, Papadopoulos S, Tzaida O, Kafiri G, Kyriakou V, Markaki S, Papaspyrou I, Karagianni E, Pavlakis K, Toliou T, Scopa C, Papakostas P, Bafaloukos D, Christodoulou C, Fountzilas G: Evaluation of the prognostic and predictive value of $\mathrm{p} 53$ and $\mathrm{Bcl}-2$ in breast cancer patients participating in a randomized study with dose-dense sequential adjuvant chemotherapy. Ann Oncol 2006;17: 1504-1511.

38 Barbareschi M: Prognostic value of the immunohistochemical expression of p53 in breast carcinomas - a review of the literature involving over 9,000 patients. Appl Immunohistochem 1996;4:106-116.

39 Børresen-Dale AL: TP53 and breast cancer Hum Mutat 2003;21:292-300.

40 Hess KR, Anderson K, Symmans WF, Valero V, Ibrahim N, Mejia JA, Booser D, Theriault RL, Buzdar AU, Dempsey PJ, Rouzier R, Sneige N, Ross JS, Vidaurre T, Gomez HL, Hortobagyi GN, Pusztai L: Pharmacogenomic predictor of sensitivity to preoperative chemotherapy with paclitaxel and fluorouracil, doxorubicin, and cyclophosphamide in breast cancer. J Clin Oncol 2006; 24:4236-4244.

-41 Kim HA, Yom CK, Moon BI, Choe KJ, Sung SH, Han WS, Choi HY, Kim HK, Park HK, Choi SH, Yoon EJ, Oh SY: The use of an in vitro adenosine triphosphate-based chemotherapy response assay to predict chemotherapeutic response in breast cancer. Breast 2008;17:19-26.

42 Takamura Y, Kobayashi H, Taguchi T, Motomura K, Inaji $\mathrm{H}$, Noguchi S: Prediction of chemotherapeutic response by collagen gel droplet embedded culture-drug sensitivity test in human breast cancers. Int J Cancer 2002;98:450-455.

43 Herr I, Debatin KM: Cellular stress response and apoptosis in cancer therapy. Blood 2001 98:2603-2614

-44 Lowe SW, Ruley HE, Jacks T, Housman DE: p53-dependent apoptosis modulates the cytotoxicity of anticancer agents. Cell 1993;74: 957-967.
45 Lowe SW, Bodis S, McClatchey A, Remington L, Ruley HE, Fisher DE, Housman DE, Jacks T: p53 status and the efficacy of cancer therapy in vivo. Science 1994;266:807-810.

46 O'Connor PM, Jackman J, Bae I, Myers TG, Fan S, Mutoh M, Scudiero DA, Monks A, Sausville EA, Weinstein JN, Friend S, Fornace AJ Jr, Kohn KW: Characterization of the p53 tumor suppressor pathway in cell lines of the National Cancer Institute anticancer drug screen and correlations with the growth-inhibitory potency of 123 anticancer agents. Cancer Res 1997;57:4285-4300.

-47 Cimoli G, Malacarne D, Ponassi R, Valenti M, Alberti S, Parodi S: Meta-analysis of the role of p53 status in isogenic systems tested for sensitivity to cytotoxic antineoplastic drugs. Biochim Biophys Acta 2004; 1705: 103-120.

48 Aas T, Borresen AL, Geisler S, Smith-Sorensen B, Johnsen H, Varhaug JE, Akslen LA, Lonning PE: Specific p53 mutations are associated with de novo resistance to doxorubicin in breast cancer patients. Nat Med 1996;2:811-814.

49 Geisler S, Lønning PE, Aas T, Johnsen H, Fluge O, Haugen DF, Lillehaug JR, Akslen LA, Børresen-Dale AL: Influence of TP53 gene alterations and c-erbB-2 expression on the response to treatment with doxorubicin in locally advanced breast cancer. Cancer Res 2001;61:2505-2512.

50 Berns EM, Foekens JA, Vossen R, Look MP, Devilee P, Henzen-Logmans SC, van Staveren IL, van Putten WL, Inganäs M, Meijervan Gelder ME, Cornelisse C, Claassen CJ, Portengen H, Bakker B, Klijn JG: Complete sequencing of TP53 predicts poor response to systemic therapy of advanced breast cancer. Cancer Res 2000;60:2155-2162.

51 Rahko E, Blanco G, Soini Y, Bloigu R, Jukkola A: A mutant TP53 gene status is associated with a poor prognosis and anthracycline-resistance in breast cancer patients. Eur J Cancer 2003;39:447-453.

52 Bergamaschi D, Gasco M, Hiller L, Sullivan A, Syed N, Trigiante G, Yulug I, Merlano M, Numico G, Comino A, Attard M, Reelfs O, Gusterson B, Bell AK, Heath V, Tavassoli M, Farrell PJ, Smith P, Lu X, Crook T: p53 polymorphism influences response in cancer chemotherapy via modulation of p73-dependent apoptosis. Cancer Cell 2003;3:387-402.

53 Xu Y, Yao L, Ouyang T, Li J, Wang T, Fan Z, Lin B, Lu Y, Xie Y: p53 codon 72 polymorphism predicts the pathologic response to neoadjuvant chemotherapy in patients with breast cancer. Clin Cancer Res 2005;11: 7328-7333.

54 Bertheau P, Plassa F, Espié M, Turpin E, de Roquancourt A, Marty M, Lerebours F, Beuzard Y, Janin A, de Thé H: Effect of mutated TP53 on response of advanced breast cancers to high-dose chemotherapy. Lancet 2002; 360:852-854 
55 Bonnefoi H, Ducraux A, Movarekhi S, Pelte MF, Bongard S, Lurati E, Iggo R: p53 as a potential predictive factor of response to chemotherapy: feasibility of p53 assessment using a functional test in yeast from trucut biopsies in breast cancer patients. Br J Cancer 2002;86:750-755.

-56 Rouzier R, Perou CM, Symmans WF, Ibrahim N, Cristofanilli M, Anderson K, Hess KR, Stec J, Ayers M, Wagner P, Morandi P, Fan C, Rabiul I, Ross JS, Hortobagyi GN, Pusztai L: Breast cancer molecular subtypes respond differently to preoperative chemotherapy. Clin Cancer Res 2005;11:56785685 .

57 Kröger N, Milde-Langosch K, Riethdorf S, Schmoor C, Schumacher M, Zander AR, Löning T: Prognostic and predictive effects of immunohistochemical factors in highrisk primary breast cancer patients. Clin Cancer Res 2006;12:159-168.

58 Johnson KR, Fan W: Reduced expression of p53 and p21WAF1/CIP1 sensitizes human breast cancer cells to paclitaxel and its combination with 5-fluorouracil. Anticancer Res 2002;22:3197-3204.

-59 Kandioler-Eckersberger D, Ludwig C, Rudas M, Kappel S, Janschek E, Wenzel C, Schlagbauer-Wadl H, Mittlböck M, Gnant M, Steger G, Jakesz R: TP53 mutation and p53 overexpression for prediction of response to neoadjuvant treatment in breast cancer patients. Clin Cancer Res 2000;6:50-56.

-60 Noguchi S: Predictive factors for response to docetaxel in human breast cancers. Cancer Sci 2006;97:813-820.
61 Geisler S, Børresen-Dale AL, Johnsen H, Aas T, Geisler J, Akslen LA, Anker G, Lønning PE: TP53 gene mutations predict the response to neoadjuvant treatment with 5 -fluorouracil and mitomycin in locally advanced breast cancer. Clin Cancer Res 2003;9:55825588.

62 Andersson J, Larsson L, Klaar S, Holmberg L, Nilsson J, Inganäs M, Carlsson G, Ohd J, Rudenstam CM, Gustavsson B, Bergh J: Worse survival for TP53 (p53)-mutated breast cancer patients receiving adjuvant CMF. Ann Oncol 2005;16:743-748.

63 MacGrogan G, Mauriac L, Durand M, Bonichon F, Trojani M, de Mascarel I, Coindre JM: Primary chemotherapy in breast invasive carcinoma: predictive value of the immunohistochemical detection of hormonal receptors, p53, c-erbB-2, MiB1, pS2 and GST pi. Br J Cancer 1996;74:1458-1465.

64 Niskanen E, Blomqvist C, Franssila K, Hietanen P, Wasenius VM: Predictive value of c-erbB-2, p53, cathepsin-D and histology of the primary tumour in metastatic breast cancer. Br J Cancer 1997;76:917-922.

65 Hamilton A, Piccart M: The contribution of molecular markers to the prediction of response in the treatment of breast cancer: a review of the literature on HER-2, p53 and BCL-2. Ann Oncol 2000;11:647-663.

66 Lerebours F, Bieche I, Lidereau R: Update on inflammatory breast cancer. Breast Cancer Res 2005;7:52-58.

67 McGill G, Fisher DE: p53 and cancer therapy: a double-edged sword. J Clin Invest 1999;104:223-225.

-68 Bunz F, Hwang PM, Torrance C, Waldman T, Zhang Y, Dillehay L, Williams J, Lengauer C, Kinzler KW, Vogelstein B: Disruption of p53 in human cancer cells alters the responses to therapeutic agents. J Clin Invest 1999; 104:263-269.
69 Castedo M, Perfettini JL, Roumier T, Andreau K, Medema R, Kroemer G: Cell death by mitotic catastrophe: a molecular definition. Oncogene 2004;23:2825-2837.

70 Moreno CS, Matyunina L, Dickerson EB, Schubert N, Bowen NJ, Logani S, Benigno BB, McDonald JF: Evidence that p53-mediated cell-cycle-arrest inhibits chemotherapeutic treatment of ovarian carcinomas. PLoS ONE 2007;2:e441.

71 Bataille F, Rümmele P, Dietmaier W, Gaag D, Klebl F, Reichle A, Wild P, Hofstädter F, Hartmann A: Alterations in p53 predict response to preoperative high dose chemotherapy in patients with gastric cancer. Mol Pathol 2003;56:286-292.

72 Burdelya LG, Komarova EA, Hill JE, Browder T, Tararova ND, Mavrakis L, DiCorleto PE, Folkman J, Gudkov AV: Inhibition of p53 response in tumor stroma improves efficacy of anticancer treatment by increasing antiangiogenic effects of chemotherapy and radiotherapy in mice. Cancer Res 2006;66:93569361.

73 Ventura A, Kirsch DG, McLaughlin ME, Tuveson DA, Grimm J, Lintault L, Newman J, Reczek EE, Weissleder R, Jacks T: Restoration of p53 function leads to tumour regression in vivo. Nature 2007;445:661-665.

74 Selivanova G, Wiman KG: Reactivation of mutant p53: molecular mechanisms and therapeutic potential. Oncogene 2007;26: 2243-2254.

75 Gudkov AV, Komarova EA: The role of p53 in determining sensitivity to radiotherapy. Nat Rev Cancer 2003;3:117-129. 